\title{
Utilization of Social Networks among Saudi EFL Learners: Trends and Uses
}

\author{
Dr. Mubarak Alkhatnai \\ College of Languages and Translation, \\ King Saud University, Saudi Arabia
}

doi: 10.19044/esj.2016.v12n35p464 URL:http://dx.doi.org/10.19044/esj.2016.v12n35p464

\begin{abstract}
The aim of this paper is to investigate the use of social networking sites among learners of English as a foreign language (EFL) in Saudi institutions of higher education. The actual study was conducted at the King Saud University (KSU). Reports on the extent to which the students are familiar with social media and the manner in which they utilize the technology were obtained. The research also examines the perception of students regarding the use social networking sites in their learning. The percentage of students using the social media and their frequency of visiting the sites also form part of the discussion of this paper. This is in an attempt to draw a clear picture of how the utilization of this new technology is emerging in Saudi higher education. The findings are discussed in light of students' actual use and their perceived beliefs about the use of such technologies in their learning and social life.
\end{abstract}

Keywords: Social Networking, Saudi, Higher Education, technology, perceptions, EFL, ICT

\subsection{Introduction}

King Saud University (KSU) is one of the oldest and most prestigious tertiary institutions in Saudi Arabia. Notably, the institution has undergone a huge transformation and improvement in the last couple of years. However, this can be noticed with some of the most evident signs of these changes occurring, such as the acquisition and use of information and communication technology (ICT) resources. Besides providing the necessary physical ICT tools, the university has gone a long way in encouraging and training its teaching staff and students to embrace technology to facilitate the content delivery and learning process respectively. Although this innovation process happened for different reasons, it was not accompanied with enough research into how this process affected the students and teachers, as well as the 
university itself as an institution. In fact, it is surprising that so little empirical research has been published on students' general use of technology in the context of Saudi higher education. As a result, the researcher was not able to locate any research on the use of SNSs in this context. Therefore, the hope is that this paper will fill this missing gap.

Notably, KSU's stance on SNSs is also clear. The university has its Facebook page, Twitter account, and YouTube channel, as well as various blogs and virtual forums. A clear example of the involvement of students in these SNSs is the presence of the university forums (http://www.cksu.com/vb/), where more than 103,000 members are registered as active members. The level of usage of social media at KSU is a reflection of the manner in which the technology is increasingly being utilized in Saudi Arabia. Cummins (2015) noted that Saudis are among the most active individuals on social media in the Arab world.

\subsection{Justification of the Study}

The social world is continuously changing, and there is need of making educational methods dynamic to enable students to enjoy a fulfilling and socially relevant learning experience. Despite the penetration of social media in the society, an argument has been advanced that the education sector, especially higher education institutions, has failed to keep pace with these technologically driven changes. Therefore, this notion is particularly the case because most people involved in higher education are consumers of technology and are by extension well entrenched in the use of social media. While the unresolved concerns about the use of social networks can be cited as a hindrance towards their adoption, educators should understand the fact that the $21^{\text {st }}$ Century learner is quite different from those of the previous generation. Furthermore, this crop of students is scarcely limited to the knowledge of life and widely comprehends the latest technology that is typical of the current social environment (Buck, McInnis, \& Randolph, 2013). Based on this background, higher education is at the risk of alienating them if it fails to integrate these technologies properly in the learning process (Levin \& Arafeh, 2002; Oblinger \& Oblinger, 2005).

\subsection{Research Questions}

i. To what extent do King Saud University students use social networking sites?

ii. What do the students use the social networking sites for?

iii. Are there barriers that hinder the students' use of such technologies in their personal as well as academic life?

iv. To what degree do students use the social networking sites for study and recreation? 


\subsection{Literature Review}

\subsection{Web 2.0 and Technological Advancement}

Technology plays an increasingly important and fundamental role in our daily lives. Thus, it enables increased number of people to interact. According to Silva, Rahman, and El Saddik (2008), the web is a medium that allows users to access and share information in the modern society. The emergence of Web 2.0 technologies, in particular, has revolutionalized how people socialize with one another and carry out their routine activities. Unlike Web 1.0 which is "static, centralised, content-based, readable, rigid and individual", Web 2.0 is "dynamic, distributed, service-based, writeable, loosely couple and social” (Hamid, Chang \& Kurnia, 2009). However, the main difference between the two types lies in the quantity of interaction between the sites and web users, as well as in the discussed authority in both types. While users in Web 1.0 are considered as passive receivers, the users in Web 2.0 are engaged as active participants. This dynamic nature of Web 2.0, coupled with the increased availability of mobile technology, has been embraced by so many people. Besides, the presence of hand-held mobile devices such as smartphones has made things much easier for users due to their ability to have access to a steady stream of Internet information. The Internet has also become affordable almost anywhere in the world, making it readily accessible to users on mobile devices. Indeed, the widespread use of social networking sites is a sure testament to the popularity of Web 2.0 technologies in the current society.

Notably, the widespread interest in the technology has developed so fast because Web 2.0 itself has been in existence for a short time. Most of the SNSs were launched just over a decade ago, such as Friendster that was established in 2002. Thus, they are relatively new. Despite the short time, the technology has gained huge amounts of popularity among the users of the Internet. Notwithstanding the mass implementation of these technologies, Franklin and Harmelen (2007) stated that Web 2.0 is rather a young technology and has several unresolved problems and issues, especially in higher education settings. First, maintaining intellectual property rights (IPR) for the material that universities members and external contributors create and modify is a real challenge. Educators have also not been able to settle on suitable pedagogies for use with Web 2.0, as well as pedagogic approaches that the use of this technology will enhance. Other issues that remain unresolved include how to evaluate material that can be collectively created. Susequently, this is open to continuous change, and the choice of the types of systems that suit institutional use. How best to roll out Web 2.0 services in a university and whether it is better to have the services hosted within the institution or elsewhere also poses a challenge. Accessibility, control over content, data preservation, integration with institutional systems, data 
ownership, visibility and privacy, the longevity of data, staff and student training, and information literacy are still issues of concern (Franklin \& Harmelen, 2007).

Besides, due to the young nature of Web 2.0, it is difficult to give recommendations and solutions to the concerns mentioned above. As such, it is the existence of the insufficient empirical data on how these SNSs are used which gave this research its validity. In fact, most of the research in this field has just emerged (Boyd \& Ellison, 2007). The immaturity and unavailability of social media research also shows that the concerns are not related to a certain field, but are in fact related to almost all fields of life where social media can be used and applied.

\subsection{Social Networking Sites}

Social networking sites are software that enables people to connect, collaborate, and form virtual communities over the World Wide Web, through the use of computers or handheld devices. In addition to allowing participants to interact with others and maintain connections, these websites also allow visitors to share content, send emails, post comments, build web content, and take part in live activities such as chats, whether is text, voice, or full video. With Web 2.0 technologies, SNSs are increasingly developing in numbers and they specifically targets the interests of different users. An example of a fast-spreading SNS is Facebook. Launched in 2004, the social site had about 400 million active users in the first quarter of 2010, with the number increasing to 1.65 billion users in the first quarter of 2016 as shown in Figure 1. In 2010, each Facebook user had an average of 130 friends and people spent a cumulative time that amounted to over 500 billion minutes on Facebook on a monthly basis. In addition to accessing the available content on the site, Facebookers themselves each add an average of 60 items a month to this social media platform (Facebook, 2010).

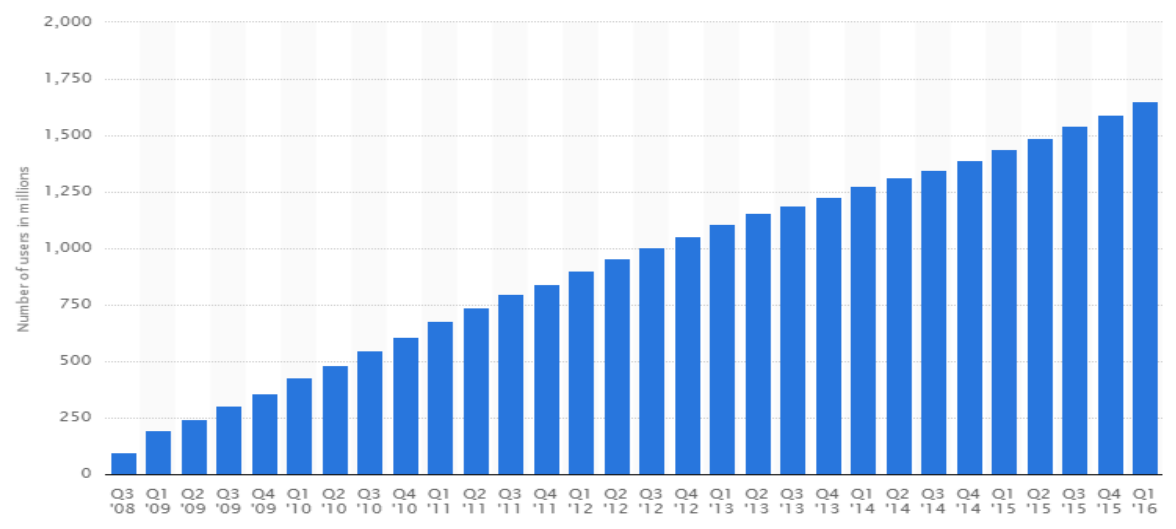

Figure 1. Growth in number of active Facebook users from 2008 to 2016 
Consequently, there have been many attempts to categorise SNSs according to either the purpose for which they were built, or their respective targeted audiences. For example, when considering the purpose of a given SNS, some sites such as LinkedIn are specifically work-related, while others like Friendster focus on building relationships. Sites such as Facebook are more student-oriented, while the likes of MySpace are interest-oriented (Ellison, Steinfield, \& Lampe, 2007). Cavazza (2008) introduced the "Social Media Landscape” and divided social media into ten different categories. These include publication tools, sharing tools, discussion tools, social networks, micro-publication tools, live cast, social aggregation tools, virtual worlds, massively multiplayer online gaming (MMO), and social gaming (Cavazza 2008). In his quest to categorise SNSs, Solis (2008) introduced "The Conversation Prism," describing it as "the art of listening, learning and sharing." Furthermore, he introduced the following graphical prism to illustrate the wide array of social media tools available today.

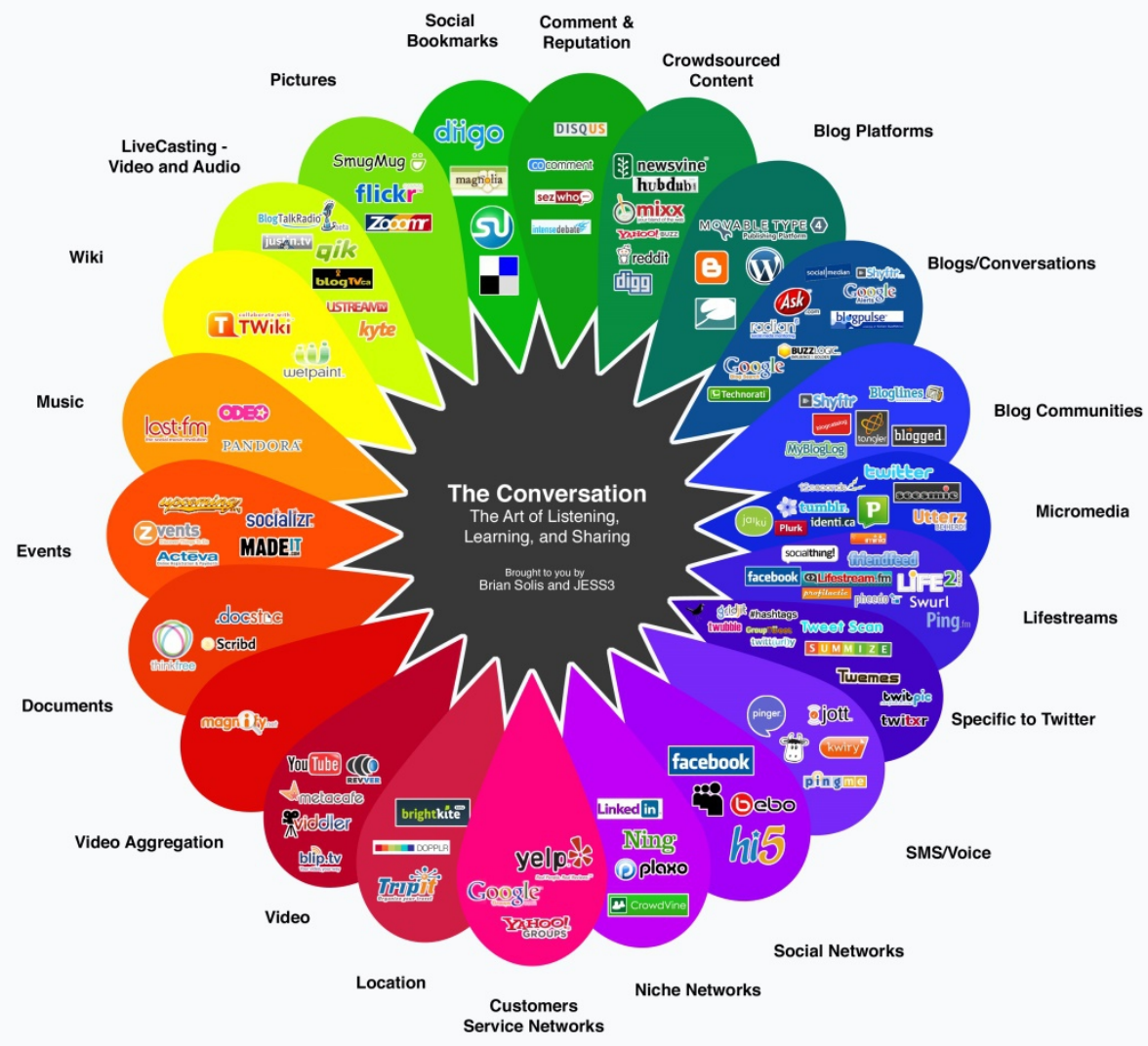

Figure 2. Conversation Prism (Solis, 2008) 


\subsection{Consumers of Social Networking Sites}

Many researchers believe that SNSs were created for and used mainly by teens and youth (Boyd, 2007). In essence, some of these SNSs were created and used solely by college students. Facebook, for example, started with college students and was initially based on invitation only. Therefore, Prensky (2001) describes the characteristics of the typical student coming to universities nowadays and compares them with the earlier generations. He classifies the present day college students as Digital Natives, who are the first generation to have grown up with this new technology. Essentially, the Digital Natives have spent their entire lives accessing and using toys and tools of this digital era, including computers, cell phones, video games, video cams, and digital music players (Prensky, 2001).

Prensky (2001) notes that the neural wiring and cultural practices of these students are different when compared to that of students from earlier generations, especially due to this unusual and technologically heavy upbringing. He observes that although Digital Natives have shorter attention spans, and therefore less of ability to reflect on topics, they have greater visual skills. Thus, they are also capable of concentrating on different media simultaneously and have the capacity to monitor changes and make inductive discoveries. While observing that the individual cognitive skills demonstrated by these students may not be new, he acknowledges that the particular blend and intensity of the skills are unique and new. The interaction with technology has given rise to a new generation with an entirely different combination of cognitive skills than its predecessors (Prensky, 2001).

On the other hand, Prensky (2001) presents the previous generations as individuals who are older and less comfortable with technology, labelling them as Digital Immigrants. Through this rhetoric of dividing people according to their technology usage, researchers have created what is known as the Digital Divide. This divide has encouraged and presented critical implications and consequences for learning and teaching. According to Buck, McInnis, and Randolph (2013), today's students are quite different from their predecessors in that they want to be part of a learning process that actively engages them and gives them more opportunity to exercise autonomy over the educational experience. Therefore, the conventional techniques of basic lecturing that have worked well in the past are no longer appealing to them. Instead, they thrive in the use of technological devices which are adorned by captivating applications that make their learning experience more attractive. Nasser (2014) notes that as mobile devices get more advanced, the development of appropriate educational programs will greatly restructure the learning environment. 
Notably, some higher education institutions are making attempts to see to it that their teaching staff and students utilize these technologies by undertaking research about the merits and disadvantages of social media on educational outcome. However, without having first established a solid base of empirical data on which to analyse the use of the technologies, the process of establishing their relevance can only be futile. Hence, this paper is an empirical investigation into the popularity and use of these technologies within a fairly developing system of higher education. It functions as a trail to map the use of SNSs in the Saudi HE sector. This research is particularly important for being conducted in a society where the use of technologies is not, in general, thoroughly investigated. However, it is the researcher's hope that this work will provide a basis for more research in the future on this topic within the Saudi HE sector.

\subsection{Methods}

The data presented in this research is drawn from a comprehensive survey that looked into the use of ICT among the students of KSU. Data collection was conducted using a questionnaire that was distributed to university students via a web-based survey tool. The questionnaire was based on the EDUCAUSE Study of Undergraduate Students and Information Technology that was undertaken by EDUCAUSE in 2008, to investigate the use of ICT among college students in the USA. Since the survey has already been used and validated, an authorisation to use the same survey was granted before this study was conducted. The survey was distributed to around 1500 students with representatives from the Preparatory Year (PY) and First Year (FY). While the former is the first year of university study that is mainly aimed at preparing the students to join the university successfully, the latter comprises of students who have already passed their PY and have just started the first year in their area of study. Data collection was carried out in line with the ethical requirements of KSU. Also, participation was voluntary and confidential. When the data for the main research were collected and investigated, the section that concerned the students' use of SNSs was presented in the current study.

\subsection{Results}

A total of 1479 students responded to the survey, representing 98.6 percent of the targeted sample of 1500 students. This figure construed a huge response rate, and the demographics of this research sample are presented in Table 1 below. Most of the respondents were males (63.2\%), while the rest (36.8\%) were females. About 591 students (approximately 40\% of the respondents) were in their preparatory year, while 888 students (approximately 60\%) were students in their first year of study. 


\begin{tabular}{llcc} 
Category & & Frequency & Percentage \\
\hline \multirow{2}{*}{ Gender } & Male & 934 & 63.2 \\
\cline { 2 - 4 } & Female & 545 & 36.8 \\
\hline \multirow{2}{*}{ Class standing } & Preparatory Year (PY) & 591 & 40.0 \\
\cline { 2 - 4 } & First Year (FY) & 888 & 60.0 \\
\hline \multirow{2}{*}{ Total } & & 1479 & $100 \%$
\end{tabular}

Table 1. demographics of the research sample

Since the main aim of this research is to examine the use of SNSs among Saudi HE students, the first question in the survey required students to indicate whether they were using SNSs or not. As seen in Figure 3, the data collected showed that the majority of students, regardless of their gender or class standing, made use of SNSs. Of the 1479 students surveyed in this research, 999 students reported using SNSs. However, this constitutes 67.5\% of the whole sample, and almost double the number of students who reported not using SNSs. Those non-SNSs users comprised a total of 480 students, which equated to $32.5 \%$ of the whole research sample. Notably, there is a difference in the percentages of students using SNSs in Saudi Arabia and the United States. Similar studies conducted in the US reveal that $85.2 \%$ of the American HE students use at least one of the SNSs (EDUCAUSE, 2008). Evidently, the difference is in actuality, and it is not that significant when one takes into consideration the differences between the two contexts more so given that $67.5 \%$ of Saudi students use social media.

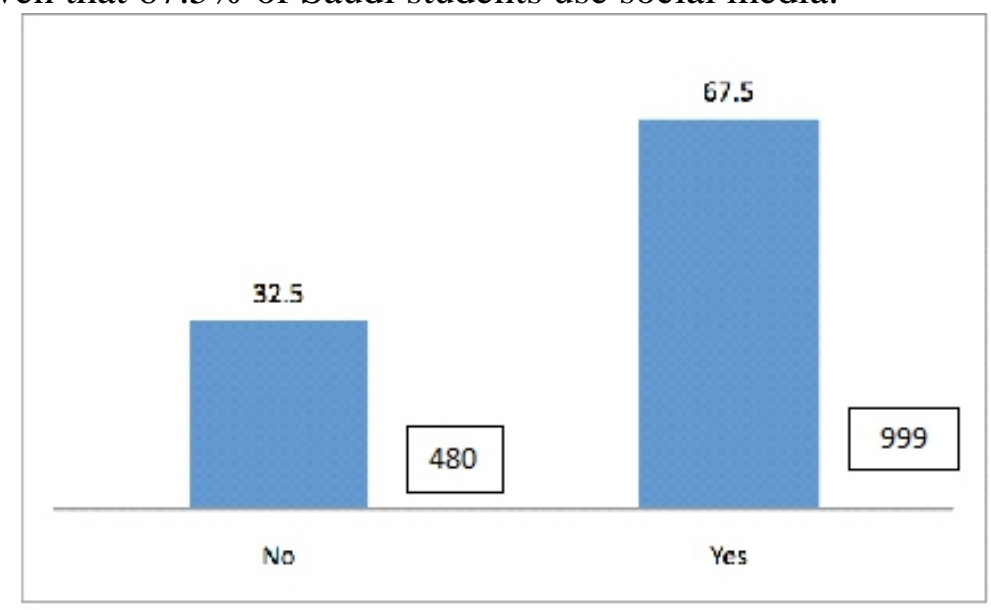

Figure 3. Students familiarity with SNSs

Since the majority of students reported familiarity with SNSs, the next question dealt with the amount of time spent on using any type of SNS. Figure 4 shows the number of hours spent weekly on accessing SNSs. About $36.1 \%$ of the students reported accessing SNSs for about 20 to 30 hours per week. If considered as a daily average, this amounts to a little more than an 
hour a day. The second highest response showed that $24.1 \%$ of students accessed SNSs, on average, for 10 to 20 hours per week. The third group of students $(9.9 \%)$ reported using SNSs on average for 30 to 40 hours per week. On the two far ends of the spectrum, $9.3 \%$ of the sample reported using SNSs less than 10 hours per week, and another $2.7 \%$ of the sample reported using SNSs for more than 40 hours per week. Therefore, it is interesting to note that if the two highest scores are combined, then $60.1 \%$ of the students spent an average of 20 hours per week using SNSs. When compared to the amount of time that students spend in their universities and colleges, this average of 20 hours per week is a reasonably large amount of time. An interesting question here is on what types of activities students engaged in on these sites during this time. However, this is a question that will hopefully initiate a similar study in the future.

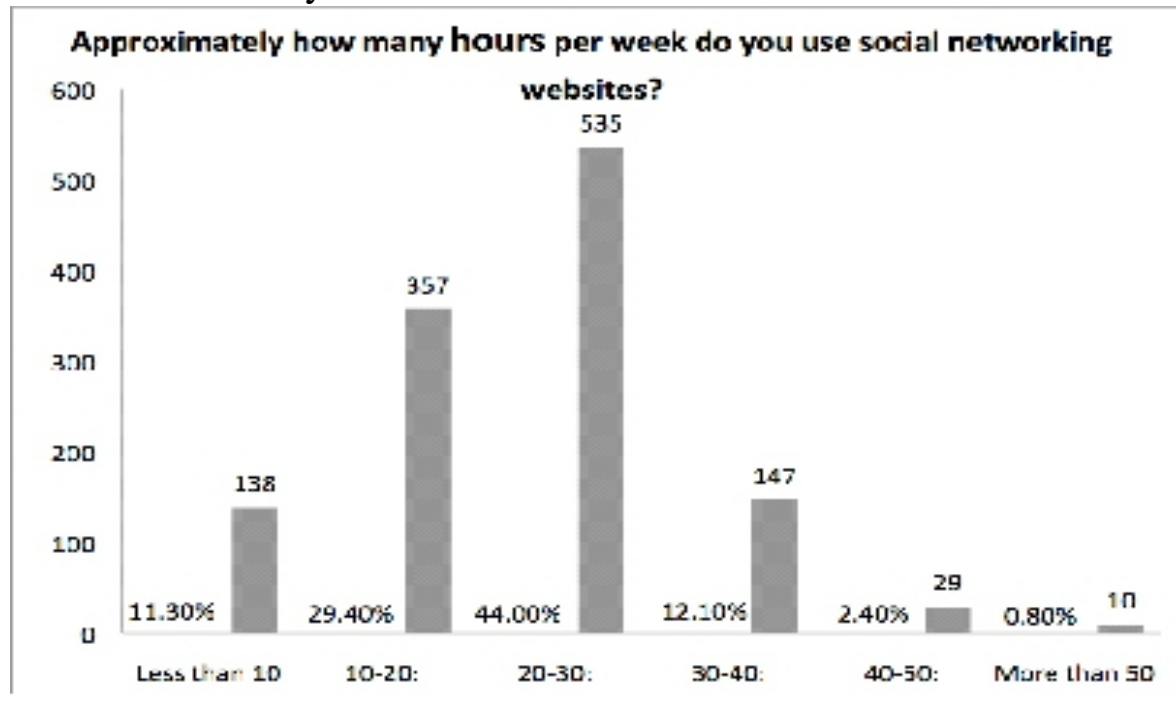

Figure 4. The weekly usage of SNSs

The participants were also asked to list the SNSs that they used and they also indicated their preference. The first interesting fact that this question highlighted is that many students reported using more than one SNS as indicated in Figure 5. Numbers indicate that students picked more than one SNS as their favourite SNS. However, WhatsApp dominated the students' preferences among all the other SNSs. About 72\% (1128 students) of the sample chose WhatsApp as their most preferred social networking tool on the Internet. This trend slightly varies from the choice of American HE students, who also expressed a preference for Facebook when the same survey was administered to them in 2008 (EDUCAUSE, 2008). According to Goad and Mooney (2008), UK students also prefer Facebook to other SNSs. In Saudi, only 466 students accounting for $31.5 \%$ of the respondents 
indicated that they use Facebook. Twitter and Snapchat are among other popular SNSs, registering 849 and 505 students respectively who prefer to use them. The less popular SNSs, as reported by Saudi students, included Yahoo! 360, Windows Live, Bebo, LinkedIn, and other SNSs which are considered to be less popular, such as Netlog.

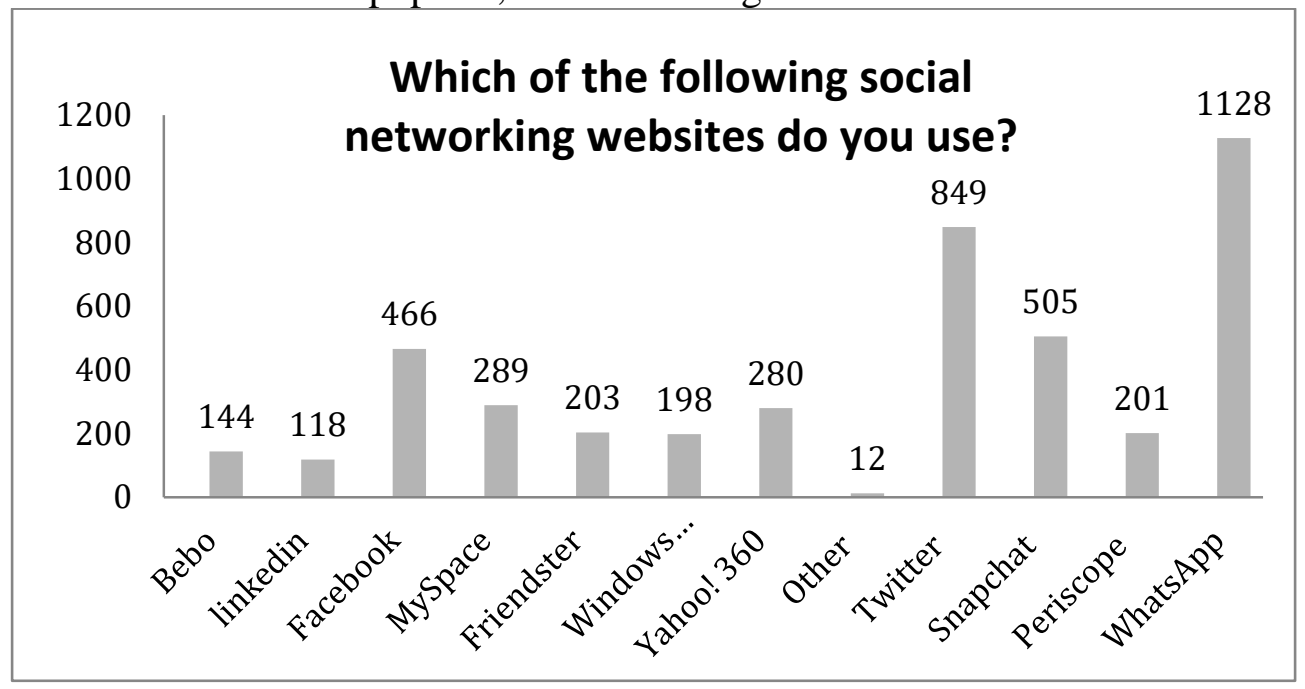

Figure 5. SNSs popularity among Saudi HE students

Some of the significant concerns which the current study tried to investigate were the reasons why Saudi HE students made use of SNSs. Figure 6 illustrates the main reasons students gave for using SNSs. Most of the Saudi HE students gave communication with their classmates and instructors about topics related to their study as the primary reasons why they use social media. Although the question was general and the survey asked about 12 different uses, students marked the uses of SNSs that were related to their study more than all of the other reasons. All the other responses were distributed on the other uses that the survey suggested. The second set of reasons included sharing photos, music, files and other works; participating in special interest groups; and using SNSs for professional activities such as job networking and so on. The last set of reasons students gave for using SNSs varies between making new friends and building new relationships. Consequently, the results for this question differed greatly from the responses of the American HE students who responded to the same survey. While American students favoured the social uses of SNSs, such as making new friends and connections, Saudi students favoured these uses less. Hence, this point raises a cultural difference that is worth investigating. Another interesting fact worth investigating is that American students responses varied based on age and gender. While younger American students favoured the social uses of SNSs, their older counterparts favoured more 
professional activities such as professional networking. Female American students favoured sharing photos, music and work more than their male counterparts. Thus, the age and gender factors will be worth considering if the same investigation about the Saudi students is undertaken.

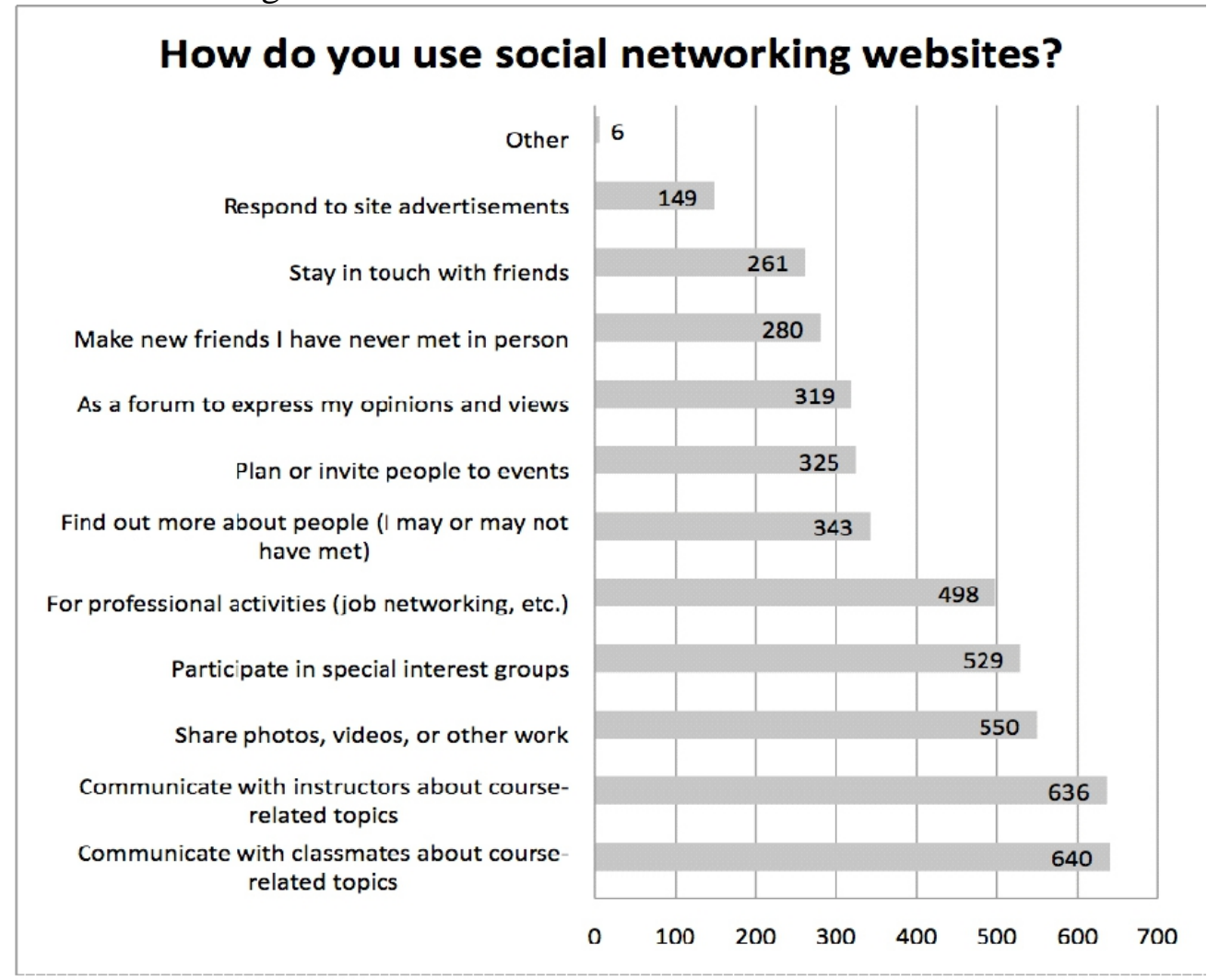

Figure 6. SNSs usage among Saudi HE students

The study also investigated the perceived barriers that may hinder the students' use of SNSs. The survey asked about eight main obstacles of using SNSs and left an open choice for any barriers that were not included. The most perceived barrier was access to SNSs and these types of technologies. The Internet in Saudi Arabia is filtered, and some certain contents are blocked. As a result, students perceived this as a major barrier. This finding is in tandem with results from other studies that have investigated various barriers to using technology in the Saudi context (Al-Sharhan, 2002; AlShibl, 2007). The second most perceived barrier among the students was related to security and their concern about the misuse of personal information. The third barrier was once again related to access, specifically access to and quality of the available network. Although KSU has provided the students with free Internet access via its own network where students can 
access the World Wide Web using their pre-provided web information, the speed and coverage of this network is still below international standards. As a result, it is therefore perceived as a barrier. It is worth mentioning here that students who cited other barriers apart from the ones provided in the questionnaires focused on the cultural view of SNSs and how their use is perceived as an improper academic behaviour. When comparing these barriers to those which were perceived by American students, the results show very great differences. While Saudi students cited access as the most prominent barrier impeding their use of SNSs, this was the least prominent barrier for their American counterparts. Another difference lay in the fact that American students perceived personal attitudes towards SNSs as being their most significant barrier. They reported that they did not use SNSs because they did not like them, or were not interested in them. However, a significant number of respondents from both studies agreed that privacy concerns might be considered as one of the barriers that hinder students' use of SNSs on both sides.

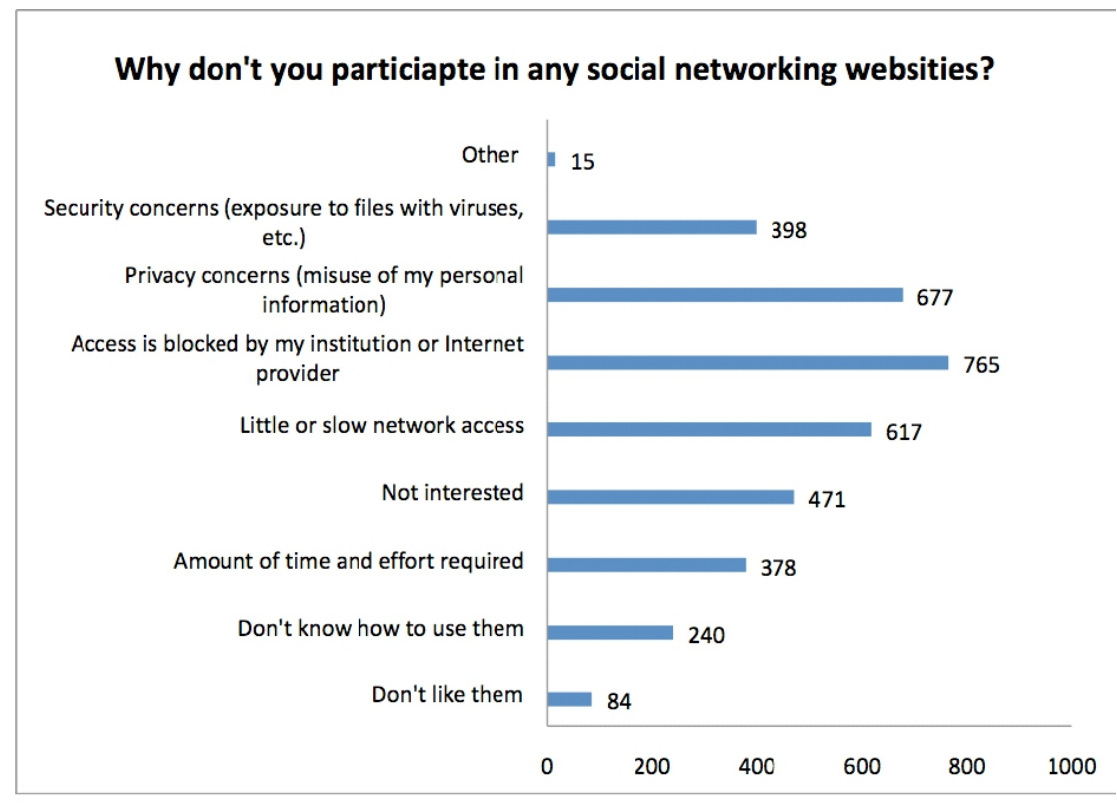

Figure 7. Barriers to not using SNSs

The next stage of the undertaken research looked at how often students use SNSs for their studies in comparison to how often the sites are used for recreational purposes. In the case of both study and recreation, the median frequency of the use of SNSs among this research sample was on a monthly basis. However, when we compare the two categories, it is clear that the recreational use of SNSs happened more frequently than the professional use of SNSs. For example, if we look at the use of SNSs on both a daily and 
several times per week basis, we notice that the recreational use of SNSs exceeded the professional use. In addition, when we look the use of SNSs over a longer range of time, such as a quarterly or yearly basis, we noticed that Saudi students' use of SNSs for study happened more frequently than the use of SNS for personal interactions. Therefore, the comparison of results from both the Saudi and the American studies yields obvious differences. Although the EDUCAUSE survey that was administered in the US did not differentiate between the students' use of SNSs for study and recreation, it is still possible to notice a difference in the frequency of use. While the median of frequency in both contexts was monthly, 85.2\% of the American students reported accessing SNSs on a daily basis. This figure, when compared to $14 \%$ of Saudi students who reported accessing SNSs on a daily basis, indicates a significant cultural difference.

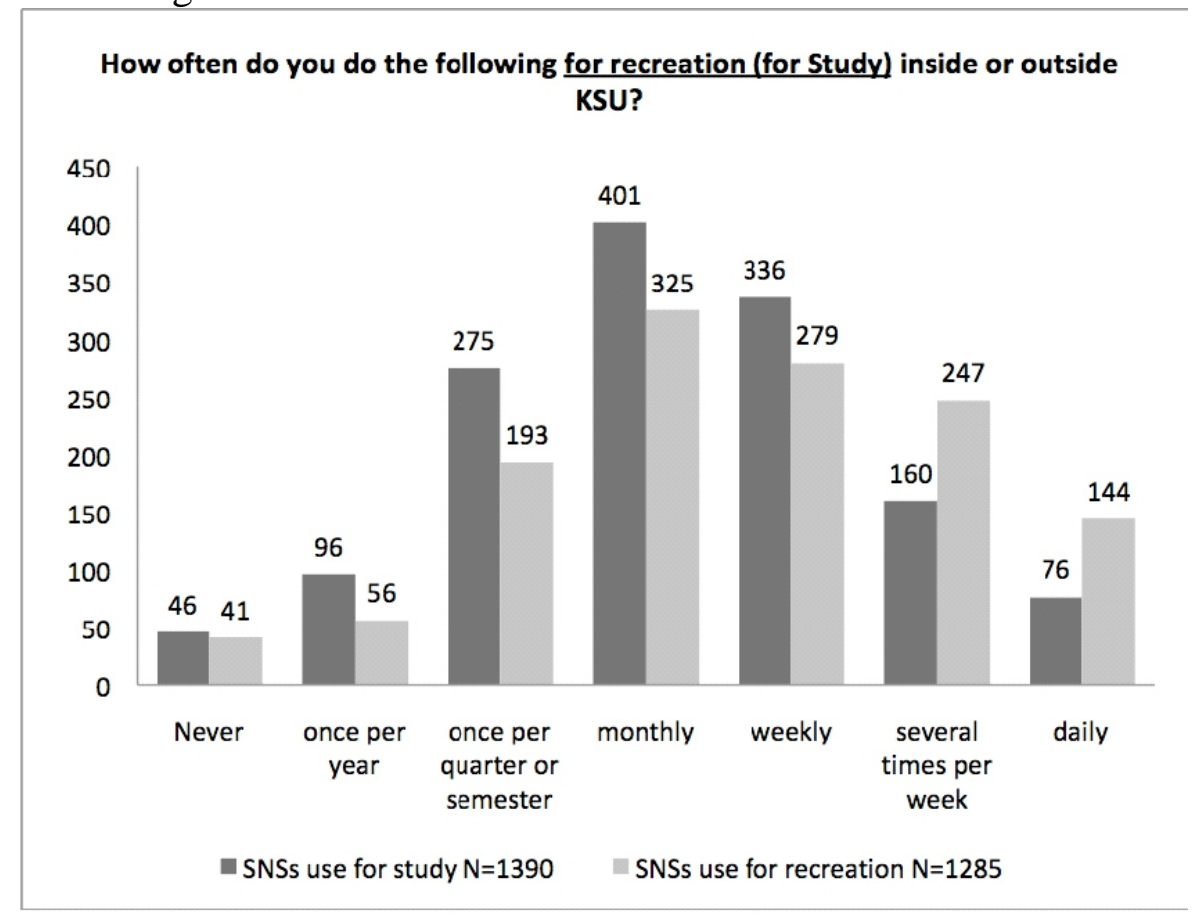

Figure 8. SNSs usage for study Vs usage for recreation

\subsection{Discussion}

The study of students' use of SNSs in King Saud University has important implications for the Saudi Higher Education context. It reveals that one notable transformation that has transpired in the social environment concerns the advancement and spread of ICT. The change has in turn affected the manner in which people interact and go about their daily activities. Individuals in various fields are increasingly finding it difficult to 
ignore the relevance and significance of social media in their operations. Chen and Denoyelles (2013), reiterates that this technology is increasingly becoming essential in institutions of higher learning. Notably, the learning and teaching process in higher education have also been affected by these developments as the use of ICT in these learning institutions is on an upward trend. Furthermore, the number of students owning mobile devices and accessing social media has considerably increased. It is evident from the study that apart from using or utilizing these technological tools to satisfy their social or personal needs, Saudi HE students have demonstrated increased tendency to use SNSs in accomplishing their educational obligations.

According to Rung, Warnke and Mattheos (2014), the efficient use of mobile devices in the current society has become an important parameter in measuring computer literacy levels among users. Evidently, the higher percentage of Saudi HE students who access social media is an indication that they are well conversant with the technology and also spend much time using the Internet. Hence, the incorporation of the use of SNSs in the learning process in Saudi's institutions of higher education would be of great help to the students, especially in enriching their learning experience. However, undertaking such implementation needs to be based on substantial evidence and reliable empirical research, a need that this study has made progress in fulfilling. When looking at the results of this investigation, one can conclude that the use of SNSs in the Saudi HE context is emerging and developing fast. In addition, educators need to pay close attention to these changes so as to better the educational system.

While some people might consider the use of SNSs as an example of the popularity of ICT, others might perceive it as going over the normal boundaries of the society. Nonetheless, the only clear fact about these results is that this is something that is happening in a moderate society, especially when we talk about technology implementation and use. Hence, the lack of homogeneity between students in this regard is evident. There are substantial differences in the utilization of and access to SNSs. This view corresponds to the assertion by Lorenzo, Oblinger and Dziubam (2006) that higher learning institutions are characterized by a highly diverse and growing student body that possesses varying information literacy capabilities. In King Saud University, for instance, the data obtained from the study indicate that nearly a third of the students do not use social media. In essence, this is not strange, and it is important to stress that simply living in a technology rich environment does not immediately entail knowing how to employ this technology optimally to enhance learning and progressing. Besides, some of the students who indicated that they do not use social media could have come from disadvantaged social backgrounds, thereby finding the 
technology a little less familiar. This knowledge is essential in guiding educators on how to conduct a proper training to both students in cases where they are considering using social media to facilitate learning.

Furthermore, an important fact that should be mentioned here is that the use of these SNSs affects the way students live, study, and perceive knowledge. This effect puts more pressure on society and educational institutions to keep up with these significant social changes. According to Rung, Warnke, and Mattheos (2014), it is essential to have a proper understanding of the skills and attitudes that primary users have towards the new tool so as to make these changes possible. They note that having such understanding is necessary for directing the development of appropriate educational innovation. Another fact related to this research is that the use of SNSs and technology, in general, is increasing in line with the affordability of such technologies. This is because increased affordability means increased access. As educators, we are asked to make the best of these technologies and match our teaching to the students' practices as best as possible. For instance, educators need to conduct continuous testing of applications that are compatible with mobile devices such as smartphones. Thus, such developments will go a long way in ensuring that students utilize the devices they have in improving academic outcome.

Notably, it is evident from the study that Saudi HE students perceive social media as a learning tool more than a platform for socialization. This finding reaffirms the observation by Rung, Warnke, and Mattheos (2014) that the current crop of students often perceives SNSs as learning tools even in circumstances where $\mathrm{HE}$ institutions or educators are yet to introduce smartphones as educational devices. Essentially, such perception or attitude towards the significance of social media avails an exceptional opportunity for teaching staff to drive the innovation process to enhance the process of incorporating the technology in class settings. Given that most respondents indicated that they employ social media in communicating with their classmates and instructors about issues surrounding their classwork, these innovations will enable them to use mobile devices. This move will help them meet their educational demands while overcoming location and time constraints. According to Lepp, Barkley, and Karpinski (2015), the challenge only comes where students see mobile devices and social networks predominantly as leisure tools. In such cases, they argue that the technology has the potential of disrupting the educational activities and adversely affects its performance.

While it is clear that SNS has the potential of facilitating the learning process in Saudi HE, these gains cannot be achieved unless various stakeholders address the various barriers that affect the effective use of this technology. For instance, despite the fact that the university has provided 
free Internet to its students, the system is highly filtered making it challenging for students to access certain sites that would be rather essential for their interaction with other hindrances. Saudi institutions of higher learning need to work towards giving their students reasonable access to content. It is understandable that information overload is disruptive to the learning process, and the challenge needs to be addressed (Al-Harrasi \& AlBadi, 2014). However, while institutions might filter the Internet to deal with the challenge, such measures might not address the problem efficiently. Oftentimes, they end up becoming barriers in themselves. Proactive approaches, such as having the administration, is used to train students and the teaching staff to use the relevant materials available on the Internet to facilitate the teaching and the learning process (Ibrahim, Salisu, Popoola, \& Ibrahim, 2014).

Evidently, more research is needed in this area. Part of the difficulty in interpreting the results of this investigation lies in the fact that we did not explicitly ask about how students make use of SNSs in their social lives, and how this social use in turn affects their use of the technology for learning purposes. As the main aim of SNSs lies in connecting people with similar interests, teachers can use these technologies to help students create connections that will help them develop and advance. Teachers can make use of the collaboration features SNSs provide to their clients. Thus, the idea of collaborative learning and its advantages for both teachers and learners are among the benefits of SNSs. As with most new technologies, some gains and shortcomings must be considered in equal fashion. The reliability and credibility of online resources are some of the main issues that teachers need to investigate, to teach their students about the reliability of conducting online research.

\subsection{Conclusion}

It is clear from this empirical research that the current generation of students favour the use of social media not only to socialize, but also to meet their educational needs and Saudi higher education is no exception. Owing to this trend, educators in the country can no longer ignore the place of SNSs in these institutions of higher learning. It is, therefore, paramount that stakeholders come together to fast-track the implementation this technology in Saudi higher education system. However, there is need of conducting further investigations to explore how the technologies available to today's students are changing their behaviour on both the social and academic aspects of their lives. Despite the fact that several studies have been conducted in various setups to establish the manner in which technology has affected the way students learn, not much has been done with the Saudi HE education system. Hence, there is need for further exploration in this area. 
This is, however, considered as a move that will ensure that the cultural differences between Saudi and other countries where these studies have been conducted are put into perspective. Such consideration is necessary since the customized investigation will relate well with the basic values and beliefs of the society towards technology. Besides, the investigation undertaken thus far will benefit from a further, in-depth qualitative investigation of the perceptions of students, and HE administrators alike on the use of SNSs in learning and better-accommodating students' differences within these technological entities. This investigation, if it occurs, will benefit other Saudi HE institutions immensely. This is because it will help to educate them on how to best invest in technologies that will enhance the students' learning, and allow them to make the best of the resources available.

\section{Acknowledgments}

The author expresses his genuine appreciation to the Deanship of Scientific Research at King Saud University, and the Research Center at the College of Languages and Translation for their candid support.

\section{References:}

1. Al-Harrasi, A. S., \& Al-Badi, A. H. (2014). The impact of social networking: A study of influence of smartphones on college students. Contemporary Issues in Education Research, 7(2), 129-136.

2. Al-Sharhan, J. A. (2002). A study of faculty members' perceptions regarding the Internet in the College of Education at King Saud University. King Saud University Journal, 14(2), 551-572. [In Arabic]

3. Al-Shibl, S. (2007). The effect of Internet filtering on accessing information by researchers. Unpublished Masters Thesis, Library and Information Sciences, Imam Mohammed bin Saud University, Riyadh, Saudi Arabia. [In Arabic]

4. Boyd, D. (2007). Social Network Sites: public, private or what? Knowledge Tree, 13 An e-Journal of Innovation(13).

5. Boyd, D. M., \& Ellison, N. B. (2007). Social network sites: Definition, history, and scholarship. Journal of Computer-Mediated Communication, 13(1), 210-230. Retrieved from http://onlinelibrary.wiley.com/doi/10.1111/j.1083-

6101.2007.00393.x/pdf

6. Buck, J. L., McInnis, E., \& Randolph, C. (2013). The new frontier education: The impact of smartphone technology in the classroom. "2013 ASEE Southeast Section Conference. Retrieved from http://se.asee.org/proceedings/ASEE2013/Papers2013/177.PDF 
7. Cavazza, F. (2008). Social media landscape. Retrieved July 30, 2008, from http://www.fredcavazza.net/2008/06/09/social-medialandscape/

8. Chen, B., Seilhamer, R., Bennett, L., \& Bauer, S. (2015, June 22). Students' mobile learning practices in higher education: A multi-year study. Educause Review. Retrieved from http://er.educause.edu/articles/2015/6/students-mobile-learningpractices-in-higher-education-a-multiyear-study

9. Cummins, J. I. (2015). Social media, public opinion, and security cooperation in Saudi Arabia. Retrieved from http://www.disam.dsca.mil/documents/research_projects/cummins.pd $\mathrm{f}$

10. EDUCAUSE Centre for Applied Research. 2008. - Students and Information Technology in Higher Education: 2008 Survey Questionnaire.l Retrieved 23/82010 from: http://net.educause.edu/ir/library/pdf/SI/ESI08a.pdf

11. Ellison, N., Steinfield, C., \& Lampe, C. (2007). The benefits of Facebook "friends": Social capital and college students' use of online social network sites. Journal of Computer-Mediated Communication, 12, 1143-1168. Retrieved from file:///C:/Users/Peninah/Documents/Drafts/Saudi\%20EFL/j.10836101.2007.00367.x.pdf

12. Facebook. (2010). Press room: Statistics. Retrieved from http://www.facebook.com/press.php

13. Franklin, T. \& Harmelen, M. (2007). Web 2.0 for content for learning and teaching in higher education. Retrieved from file://C:/Users/Peninah/Documents/Drafts/Saudi\%20EFL/Web2Content-learning-and-teaching.pdf

14. Goad, R. \& Mooney, T. (2007). The impact of social networking in the UK. Retrieved from http://melcarson.com/wpcontent/uploads/2008/01/hitwise-social-networking-report-2008.pdf

15. Hamid, S., Chang, S. \& Kurnia, S. (2009). Identifying the use of online social networking in higher education. In Same places, different spaces. Proceedings of Ascilite Auckland 2009. 419-422. Retrieved from http://www.ascilite.org/conferences/auckland09/procs/hamidposter.pdf

16. Ibrahim, N. A., Salisu, M., Popoola, A. A., \& Ibrahim, T. I. (2014). Use of smartphones among medical students in the clinical years at a medical school in Sahara Africa: A pilot study. Journal of Mobile Technology in Medicine, 3(2), 28-34. doi:10.7309/jmtm.3.2.5 
17. Lepp, A., Barkley, J. E., \& Karpinski, A. C. (2015). The relationship between cell phone use and academic performance in a sample of U.S. college students. Sage Open, 1-9. doi. $10.1177 / 2158244015573169$

18. Levin, D., \& Arafeh, S. (2002). The digital disconnect: The widening gap between Internet-savvy students and their schools. Washington, DC: PEW Internet and American Life Project. Retrieved from http://epsl.asu.edu/epru/articles/EPRU-0208-36-OWI.pdf

19. Lorenzo, G., Oblinger, D. \& Dziuban, C. (2007). How choice, cocreation, and culture are changing what it means to be net savvy. EDUCAUSE Quarterly, 1. Retrieved from https://net.educause.edu/ir/library/pdf/eqm0711.pdf

20. Nasser, R. (2014). Using mobile device to increase student academic outcomes in Qatar. Open Journal of Sciences, 2, 67-73.

21. Oblinger, D., \& Oblinger, J. (2005). Is it age or IT: First steps toward understanding the Net Generation. In D. Oblinger \& J. Oblinger (Eds.), Educating the Net Generation (pp. 2.1-2.20). Washington, DC: $\quad$ EDUCAUSE. Retrieved from http://www.educause.edu/ir/library/pdf/pub7101.pdf

22. Prensky, M. (2001). Digital natives, digital immigrants. On the Horizon, 9(5), 1-6. Retrieved from http://www.marcprensky.com/writing/Prensky\%20\%20Digital\%20Natives,\%20Digital\%20Immigrants\%20\%20Part1.pdf

23. Rung, A., Warnke, F., \& Mattheos, N. (2014). Investigating the use of smartphones for learning purposes by Australian dental students. JMIR Mhealth Uhealth, 2(2). doi: 10.2196/mhealth.3120

24. Silva, J. M., Rahman, A. S., \& El Saddik, A. (2008). Web 3.0: A vision for bridging the gap between real and virtual. Retrieved from http://www.csis.pace.edu/ ctappert/dps/d861-09/team3-read3.pdf

25. Solis, B. (2008). Introducing the conversation prism. Retrieved from http://www.briansolis.com/2008/08/introducing-conversation-prism/ 